\title{
O potencial consolador das cartas psicografadas na saúde emocional de enlutados
}

I ${ }^{1}$ Márden Cardoso Miranda Hott, ${ }^{2}$ Amanda Márcia dos Santos Reinaldo I

Resumo: A pesquisa objetivou conhecer o estado emocional de pessoas em luto complicado que receberem cartas escritas por médiuns, cuja emissão foi atribuída a seus entes falecidos. Trata-se de estudo qualitativo com abordagem quantitativa, realizado com 48 voluntários em três cenários, sendo um virtual e dois presenciais. Estes responderam a formulários estruturados compostos por nove perguntas que definiram o perfil dos participantes; e a 17 perguntas sobre o luto, elaboradas conforme critérios do Diagnostic and Statistical Manual of Mental Disorder (DSM-5), que verificou os sentimentos antes e depois da comunicação mediúnica. Concluímos que as mensagens contribuíram para melhorar a saúde emocional das pessoas provenientes dos cenários presenciais, interferindo positivamente na qualidade de vida, validando o conceito de "Cartas Consoladoras".

Palavras-chave: saúde mental; luto complicado; espiritualidade; psicografia.

\author{
1 Enfermagem Aplicada, \\ Universidade Federal de Minas \\ Gerais. Belo Horizonte-MG, Brasil \\ (estagioeeff@yahoo.com.br). \\ ORCID: 0000-0002-2791-8677 \\ 2 Enfermagem Aplicada, \\ Universidade Federal de Minas \\ Gerais. Belo Horizonte-MG, Brasil \\ (amandamsreinaldo@gmail.com). \\ ORCID: 0000-0003-0283-2313
}




\section{Introdução}

O Brasil é considerado o maior país espírita do mundo, com cerca de 3,8 milhões de adeptos, de acordo com os dados do Censo mais recente no país (IBGE, 2010). Oficialmente, esse número coloca o espiritismo como terceira religião mais praticada. As pessoas adeptas desta doutrina são favoráveis à possibilidade de comunicação com os espíritos e somam um contingente de 30 milhóes de brasileiros, de acordo com a Federação Espírita Brasileira (FEB, 2016).

Uma das mais populares formas de intermediação para se estabelecer a comunicação é através da psicografia, do grego psyché (borboleta, alma) e graphô (eu escrevo) (KARDEC, 1984). Esse termo é definido como o registro, por meio da escrita, da transmissão do pensamento dos espíritos, utilizando-se de um interceptor com capacidade para tal. O portador desta faculdade é denominado "médium", termo em francês que é originário do latim medium, meio, intermediário. Vale ressaltar que essa aptidão independe da condição moral, intelectual ou religiosa de quem a detém (KARDEC, 1984).

A prática da psicografia ocorre frequentemente nos centros espíritas em reunióes fechadas ou públicas, e permanece instigando o interesse das pessoas que buscam uma resposta para seus questionamentos. Contudo, a escrita mediúnica é marcada historicamente pelas controvérsias que provoca e pelo fascínio que desperta. As bases norteadoras da maioria dos ambientes que se valem da psicografia estão pautadas na tríade filosofia, ciência e religião, para significar a codificação kardequiana que se tornou mais conhecida no país através do médium Chico Xavier. Este, dentre outras atividades, popularizou a escrita mediúnica das "Cartas Consoladoras", que atualmente conta com médiuns continuadores, anônimos e famosos (SILVA, 2016).

Apesar da diversidade de opiniōes, o teor da psicografia é o que dará validade ao fenômeno, conforme a credibilidade de quem a emitir e a credulidade de quem a receber, sendo ambas as condiçôes um critério pessoal. Assim, para aqueles que buscam conforto por esse meio, as "Cartas Consoladoras" são entendidas como mensagens espirituais que podem aliviar o sofrimento de pessoas que vivenciam a situação do falecimento de um ente querido de maneira intensa e significativa, sugerindo estarem em luto complicado (LC).

Entende-se por LC a desorganização emocional prolongada que impede a pessoa de retomar suas atividades com a mesma qualidade de antes da perda (FRANCO, 
2010). Essa evolução desfavorável do luto considerado "normal” pode afetar a saúde física e mental, acarretando problemas como depressão, ansiedade, abuso de álcool, drogas, medicamentos, risco de doenças e suicídios (NUNES et al., 2016).

Com a intensificação da mídia, uma nova forma de produzir e divulgar as psicografias está sendo amplamente difundida pelos médiuns da cibercultura, que buscam "entregar" as mensagens através da internet, utilizando para tal as redes sociais: YouTube , e-mail, blogs, WhatsApp e sites. O uso dos meios de comunicação em massa parece estar favorecendo a disseminação deste tipo de consolo alternativo, visto que é crescente a popularidade dos intermediários receptores destas mensagens.

Comumente, várias personalidades do segmento se apresentam nas mídias sociais com o perfil "figura pública", criando fanpages que a cada dia elevam consideravelmente o número de seguidores e alcançam pessoas por todo o mundo. Pelos canais midiáticos, as agendas das sessóes de psicografias à distância ou presenciais são divulgadas, transmitidas (muitas vezes ao vivo) e comentadas. São essas pessoas que acompanham as produçóes psicográficas das cartas supostamente consoladoras, virtualmente pela internet e presencialmente nos centros espíritas, e que já estiveram na posição de destinatários das mensagens de seus entes falecidos, o foco de pesquisa. Desta forma, o objetivo do estudo foi conhecer o estado emocional de indivíduos em LC, antes e depois de receberam uma psicografia. A investigação foi desenvolvida partindo da hipótese de que as cartas mediúnicas afetam psicologicamente de forma positiva aquele que vivencia esse transtorno.

Vale ressaltar que neste trabalho ${ }^{1}$ não há pretensão na abordagem de questôes religiosas ou teológicas que perpassem pelas vertentes de fé ou credo, tampouco a veracidade do fenômeno mediúnico e das suas produçôes. O enfoque está relacionado diretamente à saúde mental de enlutados complicados que buscam, por meio da vertente espiritual, um recurso para alijamento das suas dores. A compreensão é de que a espiritualidade busca dar sentido e transcendência às questóes pessoais, enquanto a religiosidade se associa a dogmas e rituais. Contudo, muitos vivenciam o espiritual em um contexto religioso, relativizando a diferença entre os dois conceitos (BARNETT; JOHNSON, 2011).

As abordagens sobre o tema do luto (e espiritualidade) são inesgotáveis, devido a constantes atualizaçôes, principalmente se forem balizadas por pesquisadores sensíveis às demandas do mundo, flexibilizando conceitos para se deixarem desafiar por novas indagaçôes embasadas em preceitos éticos (FRANCO, 2010). Portanto, 
se faz pertinente envidar esforços no sentido de aumentar o conhecimento acerca dos "gatilhos" que podem favorecer pessoas a reverterem ou excluírem o LC de suas vidas, visando possibilitar avanços (para além do uso de psicofármacos e da psicoterapia tradicional) na saúde mental.

\section{A luta complicada do luto complicado}

Uma das vivências pessoais mais significativas na humanidade é o falecimento de um ente querido, e essa marcante situação converge em aspectos socioculturais e psicológicos que se afetam mutuamente, tecendo uma trama de significados envolvidos na construção do luto (LUNA, 2014). Diante da ausência física de pessoa falecida, é compreensível que o enlutado se entristeça, chore e tenha saudades; no entanto, a questão não é se desvincular da perda, mas como é sentida e administrada (FRANCO, 2010).

O enlutamento por morte é um processo "natural" e universal, decorrente de um fenômeno que não é passível de controle e que é inerente a todos, independentemente de qualquer variável (PEREIRA et al., 2015). Portanto, entende-se que quase todas as pessoas já passaram, estão passando ou ainda passarão por uma experiência desta natureza. Ressaltamos que os estudiosos da atualidade não trabalham mais sob a ótica de fases do luto pelo risco da ocorrência de uma avaliação injusta e preconceituosa que possa desconsiderar as particularidades humanas e generalizar a experiência (BOUSSO, 2011).

Seguindo a definição proposta e respeitada secularmente, o luto é um sentimento doloroso que acarreta a perda de interesse pelo mundo externo e a falta da capacidade de investir afeto em algo ou alguém, sendo que, com o decorrer do tempo e a aceitação da realidade, gradualmente se resolve. Porém, quando se prolonga, ocorre um processo secundário denominado melancolia (FREUD, 1996). A teoria freudiana descreve a melancolia como o luto profundamente doloroso que leva à intensificação extrema dos sentimentos relacionados ao ente falecido e à redução drástica dos sentimentos para consigo.

No entanto, o impacto que o fato gera no indivíduo, a sua capacidade de resiliência, o tipo de relacionamento estabelecido, a idade, a causa da morte e sua previsibilidade são algumas das variáveis determinantes para se definir o estado de enlutamento (MORELLI et al., 2013). Os recursos internos disponíveis são itens 
que possibilitam ou não a elaboração da perda, especialmente no que se refere ao perfil psicológico do enlutado. Assim, é entendido que o luto, quando perdura por período maior do que o esperado, de acordo com o contexto situacional, é passível de investigação diagnóstica, uma vez que pode se tornar um problema por deixar de ser um processo e passar a ser um transtorno emocional, acarretando, em última instância, prognósticos alarmantes.

A formulação considerada pelo Diagnostic and StatisticalManualofMentalDisorder - $5^{\text {a }}$ edição (DSM-5) - Perturbação de Luto Complexo Persistente (APA, 2013) - opera uma síntese integrativa das principais posições teóricas de enquadramento do LC. Nesse manual, que em termos de saúde mental é a referência usual, o enfoque para considerar o luto como um transtorno é colocado no fator temporal, considerando para diagnóstico o período de seis a 12 meses após o falecimento do ente, associado à intensidade da sintomatologia apresentada pelo enlutado.

A indicação do LC no DSM-5 constitui um avanço diagnóstico (há muito solicitado pelos pesquisadores da área), distinguindo-o do Transtorno da Depressão e da Perturbação do Stress Pós-Traumático. Em síntese, no LC todos os sintomas deletérios estão relacionados exclusivamente à tristeza em função do falecimento do ente, enquanto na depressão essa sintomatologia é generalizada, e no trauma o foco é a exacerbação do medo. Anteriormente, esses conceitos não se apresentavam estratificados. No DSM-5, o LC aparece como Transtorno de Adaptação à Morte, que gera sintomas emocionais e comportamentais como insônia, angústia, isolamento social, anedonia, irritabilidade, fadiga, baixa autoestima, pessimismo, hostilidade, impulsividade e uso abusivo de substâncias; acarretando prejuízos importantes na área social, educacional e ocupacional.

Todavia, em referencial mais abrangente, elaborado pela Organização Mundial da Saúde (OMS): Classificação Internacional das Doenças na sua versão 10 (CID10), formulado no ano de 1990 e em vigor até o momento, o luto aparece de maneira pejosa na categoria Z, sendo entendido como um desajustamento (OMS, 1999). Diante desta inespecificidade do LC, foram vários os estudos que avaliaram e defenderam a sua inclusão na CID-11 de forma clara e definida (PRIGERSON et al., 2009). Esse reconhecimento poderia favorecer a elaboração de estratégias terapêuticas de apoio biopsicossocial aos portadores deste transtorno.

No entanto, o CID-11 apresentou nova versão no ano de 2018 e foi lançado em 2019 para vigorar a partir de 2022 (CÂMARA, 2018). Embora assevere progressos, 
excluiu o luto, entendendo que este não é doença, mas sim um processo natural. Essa assertiva sobre a naturalidade do luto provocou a radicalizaçáo do tema ao não inserir um diagnóstico específico para suas complicaçóes, que, conforme sugerido pelo DSM-5 e esperado pelos pesquisadores da Saúde Mental, decorrem de um transtorno ao qual cabe atenção especial.

A prevalência global de LC é de 4,8\% (APA, 2013). Porém, há estudos apontando que cerca de $10 \%$ da população vivem esse transtorno (ZISSOK, SHEAR, 2009; WITTOUCK et al., 2011). O luto "normal" é experimentado por $80 \%-90 \%$ das pessoas (PRIGERSON et al., 2009). Desta forma, por inferência, de $10 \%$ a $20 \%$ dos enlutados são complicados. Recentemente, a incidência do problema foi de 10,43\% em pessoas que participaram da validação brasileira do instrumento PG-13, que avalia o luto prolongado (DELALIBERA et al., 2017).

Os dados levantados são mais ou tão elevados quanto outros tópicos da Saúde Mental, também relevantes, como a prevalência de 2,1\% no transtorno de acumulação (STRUCKEL et al., 2017) e 5\% do distúrbio em games (LEMMENS et al., 2015), reconhecidos ao serem inseridos no CID-11, mas que, em contraponto, não oferecem riscos iminentes à vida do portador, como no caso do LC. Pesquisas dizem que de $10 \%$ a $15 \%$ dos indivíduos que vivenciam o LC têm uma maior probabilidade de ficarem debilitados física e emocionalmente, podendo vir a ser fatal (CURRIER et al., 2008; ROGERS et al., 2008; MACCALLUM et al., 2011). E durante os cinco anos seguintes ao transtorno, esta probabilidade de mortalidade mantémse significativamente elevada (ROGERS et al., 2008). Para além, a prevalência da perturbação após os dez anos de perda é de 2,4\% (FUJISAWA et al., 2010).

A OMS incluiu no ano de 1998 a espiritualidade no conceito multidimensional de saúde ao definir esta última como o completo bem-estar físico, mental (espiritual) e social. Espiritualidade pode ser definida como um sistema de crenças que enfoca elementos intangíveis, que transmite vitalidade e significado a eventos da vida (SAAD et al., 2001). A assimilação desta perspectiva é determinante para as convicçôes de vida após a morte estarem tâo presentes na conjectura brasileira (ARRIBAS, 2011), sendo apontado como algo importante para a aceitação da morte e elaboração do luto (BUENO, 2014).

Apesar do entendimento do LC se configurar como tema atual para o cuidado em Saúde Mental, esse problema vem sendo historicamente reportado por diversos autores. Robert Burton, em sua obra The Anatomy of Melancholie, apresenta o pesar 
como causa principal do LC. Nos séculos 17 e 18, o enlutamento era considerado causa de morte e medicaçôes eram prescritas. Em 1835, o médico americano Benjamin Rush receitava ópio para enlutados e considerava que aqueles que morriam de problemas cardíacos tinham como causa o que ele chamara de coraçáo partido (PARKES, 2001).

A "descoberta" de que as emoçóes produzidas no LC podem se assemelhar a uma patologia torna relevante trabalhar o tipo de atenção oferecida, sendo primordial o incentivo à autoajuda que poderá ser fortalecida pela espiritualidade (FRANCO, 2010). O coping (enfrentamento) por esse meio está presente nas áreas das ciências médicas e sociais, abrangendo estratégias que proporcionam efeito benéfico e positivo ao indivíduo (PANZINI; BANDEIRA, 2007). Pesquisas mostraram que a espiritualidade tem significativa relevância para a maior parte da população mundial e que pacientes gostariam de ter essas questôes abordadas nos cuidados em saúde (PARGAMENT; LOMAX, 2013).

Desta forma, é válido salientar que o ser humano é, em sua constituição, detentor de entrelaçadas vertentes biopsicossociais. Neste sentido, se faz necessário reforçar para os profissionais da saúde que lidam com a complexidade do enlutamento a importância da espiritualidade como possível agente intercessor na (re)estruturação do LC e a relevância da busca pela integração de suas crenças e razóes nas açóes que visam à elaboração satisfatória do luto.

\section{Metodologia}

Trata-se de pesquisa transversal quantitativa, constituída por amostra intencional na qual os participantes foram selecionados propositalmente pelas suas experiências com relação ao fenômeno de interesse. Este tipo de amostragem baseia-se na escolha prévia dos voluntários que representam particularmente bem o evento a ser observado (FREIRE; ALMEIDA, 2008).

Os participantes são pessoas em LC que receberam psicografias de seus entes falecidos por meio virtual em "sessões à distância" (Grupo 1), através de canais da internet; presencialmente em "sessôes fechadas" (Grupo 2), e presencialmente em "sessôes públicas" (Grupo 3), ambas em Casas Espíritas.

A amostra do Grupo 1 (G1) foi extraída de mídias de acesso público e irrestrito com enfoque no apoio a enlutados (sites, blogs, Facebook e YouTube $\left.^{\oplus}\right)$. Os ambientes 
virtuais para a coleta de dados foram selecionados a partir de pesquisa prévia que indicou alta popularidade, considerando o número de inscritos, seguidores, visualizações e audiência. Neste cenário o intermediário (médium) não foi identificado. Por esses canais, houve o rastreamento de pessoas que declararam publicamente, mediante comentários em postagens, terem recebido virtualmente mensagens mediúnicas de seus entes falecidos.

A amostra do Grupo 2 (G2), na qual o destinatário não participa diretamente do momento da emissão da mensagem psicografada, mas encontra-se in loco, foi proveniente de frequentadores de um grupo espírita localizado no Estado de Minas Gerais que se dedica há mais de 20 anos à psicografia. O local foi selecionado convenientemente diante de sua reconhecida beneficência no contexto geral espiritualista. Neste ambiente há um coordenador e um supervisor da emissão das cartas que são psicografadas por médiuns diversos e entregues aos seus destinatários sigilosamente. Desta forma, também neste cenário os intermediários não foram identificados.

Para a obtenção da amostra do Grupo 3 (G3), na qual o destinatário mantém interface direta com o intermediário, houve a contribuição do médium Orlando Noronha Carneiro. O referido é psicógrafo há 35 anos, com trajetória consolidada no meio espírita. Iniciou sua tarefa psicográfica das denominadas "Cartas Familiares" sob a égide do médium Chico Xavier, do qual segue referencial de conduta, buscando augir rigorosamente as lides doutrinárias, o que justificou sua escolha como colaborador do estudo.

Neste cenário, a identificação do intermediário é questão patente, bem como dos destinatários de suas mensagens, uma vez que, sob prévia autorização, as cartas são lidas publicamente. Apesar disto, vale ressaltar que aqueles que se disponibilizaram a serem voluntários do estudo não tiveram as identidades reveladas neste trabalho. Para coleta de dados deste grupo amostral foi necessário seguir o itinerário de agenda psicográfica do médium supracitado, percorrendo três centros espíritas localizados nos estados de Minas Gerais, Paraná e São Paulo.

Os voluntários do G1 foram rastreados e convidados a participarem do estudo via Messenger in box brevemente explicativa. Aqueles dos G2 e G3 foram abordados e convidados direta e explicativamente. Diante do aceite, para todos, foi solicitado o e-mail e/ou o WhatsApp por onde se estabeleceu o contato. Por esses meios ocorreu o envio do link para acesso ao Termo de Consentimento Livre e Esclarecido (TCLE), 
que foi acionado para leitura e assinatura eletrônica, através de registro do Internet Protocol (IP) na plataforma de pesquisa OnLinePesquisa ${ }^{\odot}$

Os convites foram emitidos continuadamente, na medida em que foram captados os possíveis participantes, até que fosse atingida a taxa de resposta de 48 aceites respeitando a equidade, ou seja, 16 voluntários para cada um dos três grupos.

Foram incluídas na pesquisa pessoas que receberam mensagens psicografadas de seus entes falecidos no período de dezembro de 2017 a fevereiro de 2018 no G1; no período de março a maio de 2018 no G2; no período de setembro a outubro de 2018 no G3; e que não apresentavam comprometimento cognitivo evidentemente perceptível.

Foram excluídas da pesquisa pessoas que não se enquadraram no conceito de LC. Para tal foi disponibilizado na plataforma de acesso aos elementos da pesquisa uma pergunta seletiva que requisitou apenas "sim" ou "não" como resposta, partindo do ponto de vista do próprio participante, conforme indicativo do DSM-5, a saber: após o falecimento de seu ente, você acredita que tenha conseguido superar o fato sem grandes transtornos em sua vida? Diante da resposta afirmativa (sim), uma mensagem de agradecimento foi emitida e o acesso finalizado. No caso da resposta negativa (náo), foi aberto o acesso ao TCLE e ao Instrumento da Pesquisa contendo duas partes distintas.

$\mathrm{Na}$ primeira parte do Instrumento de pesquisa, os participantes responderam ao Formulário A (FA), sendo este estruturado, composto por nove perguntas que visaram a estabelecer o perfil social, demográfico e cultural dos voluntários do estudo. Na segunda parte os participantes responderam ao Formulário B (FB), construído especificamente para o estudo, contendo dezessete (17) questóes estruturadas e adaptadas do DSM-5, relacionadas à padronização internacional para diagnóstico de LC. Cada questão do FB ofereceu seis opções de respostas baseadas na situação emocional do enlutado antes e depois do recebimento da mensagem psicografada de seu ente falecido. Os escores das respostas para o FB foram fracionados em níveis (graus) de intensidade emocional, sendo: 1 = quase nenhuma; 2 = muito pouca; 3 = pouca; 4 = média; 5 = alta; 6 = muito alta. Portanto, a pontuaçấo seguiu a escala de 1 a 6 por questão, tanto para o tópico "antes", quanto para o tópico "depois".

Todos os dados do instrumento de pesquisa foram submetidos à análise estatística descritiva. As variáveis categóricas do FA foram expressas em percentuais. No FB ocorreu a análise das variáveis contínuas por meio do programa Statistical Package for the Social Sciences 14.0, a fim de gerar as medidas de tendência central e dispersão. 
A diferença entre as médias obtidas por questão nos períodos "antes" e "depois", indicando regressão de no mínimo um ponto em $70 \%$ das questôes (12/17), foi estipulada como meta pelas pesquisadoras, sendo este resultado considerado suficiente para se entender a possibilidade da ocorrência do progresso no estado emocional dos participantes, representando o decréscimo da robustez dos sintomas de LC.

Este estudo foi aprovado pelo Comitê de Ética e Pesquisa, Parecer: 2.419.512, resguardando o sigilo e a privacidade dos participantes, seguindo os preceitos da Declaração de Helsinque e do Código de Nuremberg, bem como a Resolução n. 466/12 do Conselho Nacional de Saúde. Todos os participantes assinaram o Termo de Consentimento Livre e Esclarecido. Não há conflito de interesse nesta produção.

\section{Resultados}

Os voluntários do estudo responderam à questão de triagem que, segundo percepção de si mesmos, afirmavam estarem em LC. No entanto, para confirmar se a amostra estava verdadeira e totalmente composta por voluntários portadores deste transtorno, checamos as respostas do FB, para além da questão norteadora do problema, considerando os parâmetros complementares do DSM-5. Estes se caracterizam pela evidência das intensidades 4 (alta) ou 5 (muito alta) em pelo menos 1 (uma) das questôes enumeradas de 1 a 4, e em no mínimo em 6 (seis) das questôes seguintes, enumeradas de 5 a 17, independente do extrato grupal. Constatamos que os $48(100 \%)$ participantes atenderam aos requisitos.

Complementando o estudo, traçamos o delineamento social, demográfico e cultural dos participantes a fim de enriquecer os dados amostrais, o que justifica o incremento do FA nesta pesquisa. Tais informaçóes proporcionaram conhecer o perfil das pessoas que desenvolvem o LC e estão apresentadas na tabela 1, a seguir: 
Tabela 1. FA: Perfil Sociodemográfico-Cultural dos participantes

\begin{tabular}{|c|c|c|c|c|c|c|}
\hline Inquérito & Variáveis & N 16 / G1 & N 16 / G2 & N 16 / G3 & N Parcial (\%) & N Total (\%) \\
\hline \multirow{2}{*}{ Gênero } & Feminino & 16 & 13 & 14 & $43(89,6 \%)$ & \multirow{2}{*}{$48(100 \%)$} \\
\hline & Masculino & 0 & 3 & 2 & $5(10,4 \%)$ & \\
\hline \multirow{4}{*}{$\begin{array}{l}\text { Faixa etária } \\
\text { (participante) }\end{array}$} & $18-32$ anos & 2 & 3 & 2 & $7(14,6 \%)$ & \multirow{4}{*}{$48(100 \%)$} \\
\hline & $33-47$ anos & 12 & 8 & 5 & $25(52,1 \%)$ & \\
\hline & $48-62$ anos & 2 & 4 & 8 & $14(29,1 \%)$ & \\
\hline & 63 ou mais & 0 & 1 & 1 & $2(4,2 \%)$ & \\
\hline \multirow{5}{*}{ Escolaridade } & Fundamental & 3 & 0 & 1 & $4(8,3 \%)$ & \multirow{5}{*}{$48(100 \%)$} \\
\hline & Ensino médio & 2 & 5 & 5 & $12(25 \%)$ & \\
\hline & Técnico & 4 & 1 & 0 & $5(10,4 \%)$ & \\
\hline & Graduação & 6 & 7 & 8 & $21(43,8 \%)$ & \\
\hline & Pós-graduação & 1 & 3 & 2 & $6(12,5 \%)$ & \\
\hline \multirow{4}{*}{ Religião } & Católica & 1 & 7 & 2 & $10(20,8 \%)$ & \multirow{4}{*}{$48(100 \%)$} \\
\hline & Espírita & 13 & 9 & 13 & $35(72,9 \%)$ & \\
\hline & Evangélica & 1 & 0 & 0 & $1(2,1 \%)$ & \\
\hline & Outra & 1 & 0 & 1 & $2(4,2 \%)$ & \\
\hline \multirow{5}{*}{ Localidade } & Centro-Oeste & 3 & 0 & 1 & $4(8,3 \%)$ & \multirow{5}{*}{$48(100 \%)$} \\
\hline & Sudeste & 9 & 16 & 13 & $38(79,2 \%)$ & \\
\hline & Sul & 2 & 0 & 2 & $4(8,3 \%)$ & \\
\hline & Nordeste & 2 & 0 & 0 & $2(4,2 \%)$ & \\
\hline & Norte & 0 & 0 & 0 & $0(0 \%)$ & \\
\hline \multirow{9}{*}{ Ente falecido } & Amigo(a) & 0 & 1 & 0 & $1(2,1 \%)$ & \multirow{9}{*}{$48(100 \%)$} \\
\hline & Avô(á) & 1 & 2 & 0 & $3(6,2 \%)$ & \\
\hline & Esposo(a) & 0 & 1 & 1 & $2(4,2 \%)$ & \\
\hline & Filho(a) & 5 & 0 & 11 & $16(33,3 \%)$ & \\
\hline & Irmã(o) & 1 & 0 & 1 & $2(4,2 \%)$ & \\
\hline & Mãe & 5 & 0 & 0 & $9(18,8 \%)$ & \\
\hline & Pai & 4 & 0 & 2 & $13(27 \%)$ & \\
\hline & Sogro(a) & 0 & 0 & 0 & $1(2,1 \%)$ & \\
\hline & Tio(a) & 0 & 0 & 1 & $1(2,1 \%)$ & \\
\hline
\end{tabular}




\begin{tabular}{lllllll}
\hline Inquérito & Variáveis & N 16 / G1 & N 16 / G2 & N 16 / G3 & N Parcial (\%) & N Total (\%) \\
\hline \multirow{4}{*}{ Causa do óbito } & Acidente & 3 & 3 & 3 & $9(18,8 \%)$ & \\
& Doença & 8 & 12 & 11 & $31(64,6 \%)$ & \\
& Homicídio & 3 & 0 & 1 & $4(8,3 \%)$ & $48(100 \%)$ \\
& Suicídio & 0 & 0 & 0 & $0(0 \%)$ & \\
& Desconhecida & 2 & 1 & 1 & $4(8,3 \%)$ & \\
Mensagem & 1 ano & 8 & 6 & 12 & $26(54,2)$ & \\
pós-óbito & 2 anos & 2 & 1 & 3 & $6(12,5 \%)$ & \\
& 4 anos & 0 & 0 & 0 & $0(0 \%)$ & $48(100 \%)$ \\
\hline
\end{tabular}

$\mathrm{N}$ = Número de participantes

A tabela 2 representa a síntese do FB elaborado a partir das variáveis indicativas de LC sugeridas pelo DSM-5, estratificadas em períodos "antes" e "depois". Este formulário representa o foco central do estudo. 


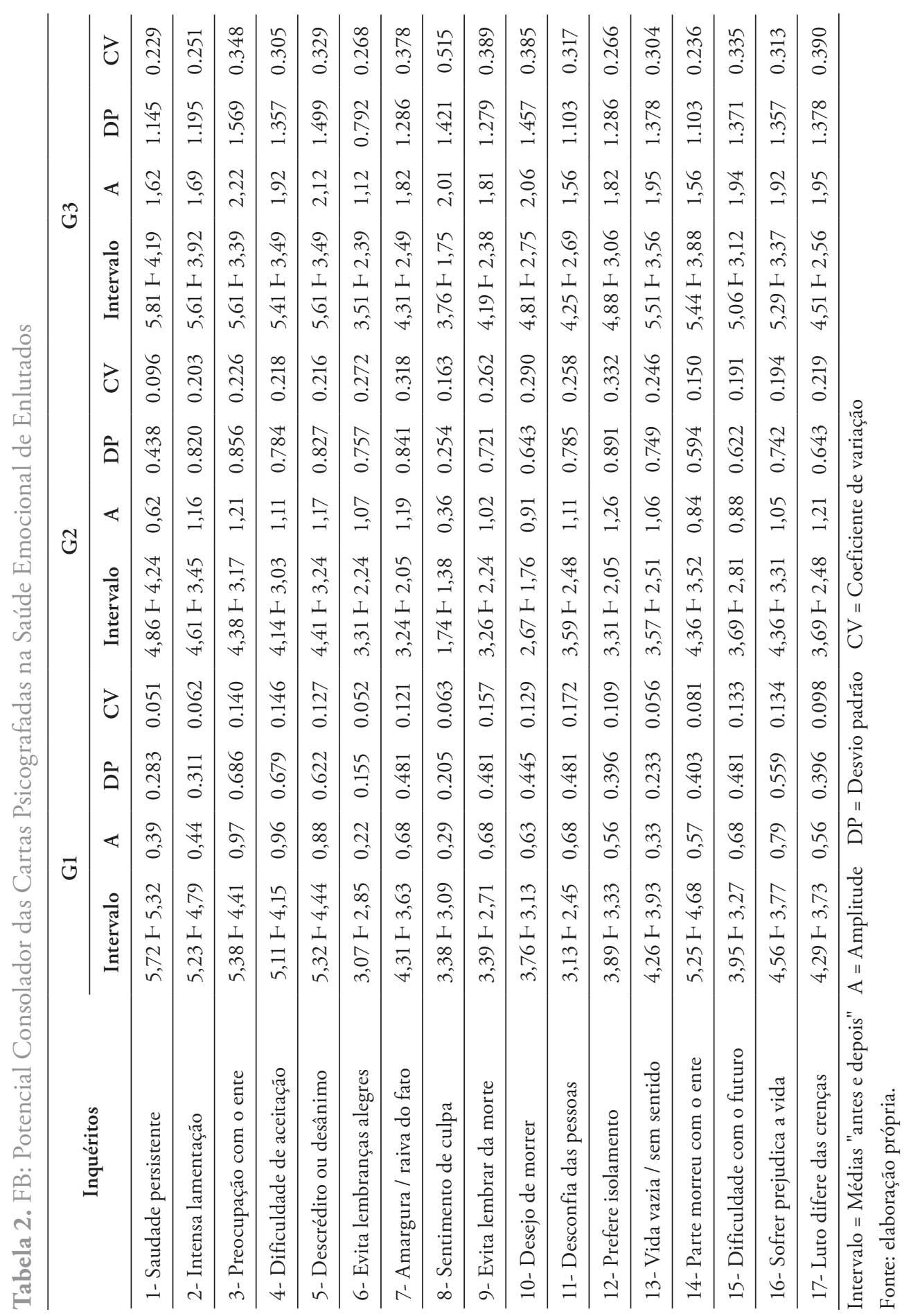




\section{Discussão}

\section{Formulário A: Sociodemográfico-cultural}

No resultado geral percebe-se a alta prevalência feminina $(89,6 \%)$ e este elevado percentual do gênero corrobora com indicadores já consolidados que apontam as mulheres com maiores possibilidades de enlutamento complicado (APA, 2013), assinalando a aparente vulnerabilidade emocional. A maior facilidade de explicitar suas dores em açóes não significa que os homens náo se enlutem, visto que o luto feminino pode ter expressóes diferentes do luto masculino (BOWLBY, 1985).

No que concerne à faixa etária, a maioria $(52,1 \%)$ dos destinatários das cartas encontra-se em plena adultez (33-47 anos), entendida como fase que engloba muitas possibilidades de experimentaçôes. Relevante apontar para a questão no LC nesse intervalo de idade, visto que é considerado o ápice da vida profícua, o que pode trazer déficits significativos nos indicadores de saúde e produtividade desta população.

Esse período de geração e/ou criação de filhos em idade infantil ou juvenil remete à probabilidade da vivência do luto por seus descendentes. Por outro lado, também nessa fase da vida, os pais e mães destes indivíduos se encontram em processo de envelhecimento, o que os aproxima mais do fenômeno da morte. As situaçôes justificam a predominância de mensagens psicografadas por filhos (33,3\%), pais (27\%) e mães $(18,87 \%)$ no resultado geral dos grupos.

Advinda na fase de senescência, a morte é interpretada como um acorde final de uma sonata, enquanto a perda de um infante é sentida como uma mutilação (ROCHA et al., 2017). O óbito de um ente mais jovem ou prematuramente pode ser visto como adverso às expectativas naturais com relação ao ciclo vital. Esta ocorrência se confirma no G3, no qual a busca de alento pelo falecimento de um filho se faz altamente presente (11/16). Contudo, se dispersa nos G1 e G2, nos quais a partida de um ente outorga ares de difícil superação entre diferentes graus de parentesco. Este resultado não descaracteriza a alusão de que a dor de genitores tenha maior significado; no entanto, engloba os demais vínculos no rol de expressividade do pesar.

As predominâncias do nível de graduação $(43,8 \%)$ e da identificação com o espiritismo (79,2\%) coadunam com o censo estatístico brasileiro mais recente, que aponta a população que se autodeclara espírita como detentora dos melhores indicadores de educação, comparados com as demais religiôes do país (IBGE, 2010). Contudo, verificamos nesta amostra que, apesar do elevado nível de instrução, 
esta variável não é um indicativo de melhor entendimento e esclarecimento das propostas espíritas, visto que o desenvolvimento do LC nessa população parece contradizer os princípios doutrinários.

Importado da França através de Allan Kardec, o elemento de destaque do espiritismo no Brasil consiste na busca pela comunicação entre vivos e seus entes queridos que partiram (AUBRÉE; LAPLANTINE, 2009). Porém, um dos alicerces da obra kardequiana está baseado na confiança de um reencontro em um mundo espiritual bem mais estruturado do que o mundo material, este em que atualmente vivemos (KARDEC, 2007). Essa perspectiva poderia constituir um significante papel consolador; no entanto, a mensagem psicografada precede esse princípio que parece só se fazer valer diante da ocorrência do intercâmbio entre os vivos encarnados e os vivos desencarnados. $\mathrm{Na}$ amostra, os preceitos doutrinários por si só não contribuíram para amenizar o LC, tendo sido necessária a busca pela "materialização" da proposta por meio da mensagem mediúnica. Em consonância com nossa confirmação, um estudo brasileiro chama a atenção por indicar que o LC apresenta maior probabilidade de se desenvolver em pessoas espíritas (ALVES, 2014).

Outro quesito notório é o fator doença $(64,6 \%)$ como causa da morte predominante, diante do entendimento de que o impacto tamanho que o óbito traumático repentino pode ocasionar é incomparável (BOWLBY, 1985). Contudo, o elemento "surpresa" pode estar presente tanto nos quadros de falecimento por doenças fulminantes quanto nas situaçôes de homicídios, suicídios ou acidentes, sendo estes pouco representativos nesta amostra. Doenças súbitas ou prolongadas, potencialmente letais e que se apresentaram de modo considerado atroz também podem favorecer o desenvolvimento do LC.

A procura por um consolo no período do primeiro ano pós-morte de um ente querido $(54,2 \%)$ indica que a superação do luto dentro deste prazo é difícil e que nos meses seguintes à perda a necessidade de um alento se faz mais intensa. É impossível definir uma data precisa para o encerramento do LC, sendo improvável levar menos de um ano (WORDEN, 1991); e a cada nova estação, em datas comemorativas ocorre a reevocação da dor (WALSH; MCGOLDRICK, 1998). Esse fato pode reforçar as diversas teorias sobre o LC, que encontram divergências na questão temporal para superação do enlutamento.

No que se refere à proveniência dos participantes, entendemos como um possível viés de pesquisa a presença marcante de voluntários oriundos da Regiáo 
Sudeste (79,2\%), visto que a maioria dos cenários de coleta de dados está situada nessa localidade, apesar de um estrato do G2 ter sido recrutado na Região Sul e da óbvia dispersão no G1, por se tratar de cenário virtual. No entanto, para o G2 e G3 o deslocamento intermunicipal e interestadual é prática comum na busca por mensagens psicografadas. Porém, esse possível translado não pode ser definido em função da abrangência da pergunta.

\section{Formulário B: Luto}

Os 17 itens sintomatológicos contidos no $\mathrm{FB}$ necessariamente não estáo presentes em todos os portadores de LC. A constatação pela interpretação do próprio participante via triagem e pela análise das pesquisadoras que identificaram a presença das sintomatologias em maior grau de intensidade fomentou o consenso entre as partes, confirmando a amostragem intencional composta totalmente por pessoas em LC.

No FB foi considerada para verificação a diferença entre as fases "antes" e "depois". Os resultados apontam para a regressão dos sintomas do transtorno em todas as variáveis de todos os grupos. Apesar disto, os participantes do G1 demonstraram menor expressividade na questão foco da pesquisa (decréscimo de amplitude), visto que nenhum dos 17 itens indicativos de LC regrediu ao ponto de corte em pelo menos 1 grau de intensidade, não apontando a melhora do quadro, conforme a casuística deste estudo.

Com o advento da "Idade Mídia", as sessóes de psicografia foram reinventadas, inovadas e disseminadas com velocidade justificada pelo meio e pelo método de comunicação que se vale de antagonismos. As facilidades de acesso às informaçóes pessoais, familiares e sociais, ao mesmo tempo em que viabilizam e universalizam a prática, tornam a mesma questionável justamente pela exposição massiva de dados. Esse fato pode levar o enlutado a não legitimar a comunicação, o que pode ter influenciado no resultado.

No G2 dos 17 itens abordados, 12 (70\%) confirmaram o pressuposto de que as cartas psicografadas afetam positivamente a saúde emocional dos enlutados complicados mediante a evidência da regressão dos sintomas, com médias $(\mathrm{M})$ que variaram amplitude (A) entre 1,02 e 1,26 e desvio padráo (DP) entre 0,721 e 0,891. Foram cinco os itens que não indicaram regressão de sintomatologia e se referem aos sentimentos de saudade, culpa, desejo de morrer, sentir que parte de si morreu junto com o ente e dificuldade para planejar o futuro. 
A saudade se apresentou com intensidade alta e se manteve entre o grau elevado. No entanto, sentir saudade daquele que não mais se faz presente fisicamente continuará fazendo parte das vivências, mas agora de uma maneira na qual se aprende a conviver com a ausência e é possível retomar a vida (TORRES, 2013). Esse sentimento é uma constante na continuidade da existência dos enlutados em geral e está relacionado à herança de uma história de vida jamais esquecida.

A culpa é entendida como irracional, correspondendo ao desgosto perante uma avaliação negativa de atitudes que foram tomadas ou não assumidas para com o ente querido (REBELO et al., 2017). Portanto, atribuir para si a responsabilidade pela morte (não a tendo) está associado à percepção de fracasso ou impotência diante da sensação equivocada do poder de impedimento, da falha nas condutas que fizeram parte da história de vida dos envolvidos ou exclusivamente diante do episódio que gerou o desfecho, a morte.

O desejo de morrer para estar com o ente é o ápice da problemática do LC por ter elo direto com a tentativa ou consumação do autoextermínio, o que é considerado como a pior de todas as tragédias humanas. Embora nenhuma patologia ou acontecimento possa prever o suicídio, existem certas vulnerabilidades que tornam alguns indivíduos mais propensos a cometer esse ato do que outros (SANTOS, 2017), neste caso o LC. Essa vontade, associada a crenças em uma vida após a morte, assinala a nutriçáo da expectativa de que morrer seria uma possibilidade de preservar o modo de relação anterior (FREITAS; MICHEL, 2014).

Menos excruciante que um sintoma sugestivo da condução para o suicídio, mas também eloquente, é a compreensão de que parte de si morreu junto com o ente. A literatura mostra que a perda de um filho, como aparece marcante neste estudo, é vivida pelas máes como a perda de uma parte de si, a amputação de um pedaço do corpo (FREITAS; MICHEL, 2014).

A dificuldade de planejar o futuro está ligada ao sentimento de desesperança, e pessoas que portam esse sentimento tendem a prever o futuro sem expectativas, perdem a motivação para prosseguir e o desejo de viver é arruinado (SANTOS, 2017). Quando um ente querido morre, ocorrem profundas rupturas, que requerem adequaçôes na percepçáo do mundo e no planejamento que viabilize a continuidade da vida, edificando novos significados que viabilizem o seguir em frente.

Quanto ao G3, houve unanimidade na constatação da regressão dos sintomas do LC, apresentando uma diferença estatisticamente significativa entre os períodos. 
Fica evidenciado que esta amostra apresentou os mais elevados níveis de intensidade sintomatológica "antes" e os menores índices "depois", com A entre 1,12 a 2,22 e DP entre 0,798 a 1.569 , contemplando os 17 itens em questão. Portanto, é possível referir que foi comprovada por meio das medidas de tendência central e dispersão que todos os itens do FB validaram a hipótese de pesquisa. O potencial de consolo foi mensurado e é factível.

Não podemos afirmar que o transtorno foi interrompido, mas ficou evidenciada a capacidade de positivar a reorganizaçáo dos sentimentos, diante da beneficência proclamada pelos participantes do G2 e especialmente no G3. Essa ocorrência nos remete à reflexão de variáveis ocultas no processo de interpretação das psicografias pelos destinatários que podem tanto interferir para sua legitimidade quanto para a refutação (como ocorreu no G1).

É provável que nos $\mathrm{G} 2$ e G3 elementos intangíveis contribuam para potencializar o consolo, como a personificação do ente falecido na escrita da mensagem, trazendo informaçóes privadas contendo o teor de que o enlutado necessitava e/ou pretendia conhecer; bem como o perfil do intermediário, incluindo sua capacidade da captação de conteúdo, altruísmo e conduta moral. Talvez esses sejam alguns dos fatores, possivelmente elegíveis pelo próprio destinatário, os determinantes para conduzir a eficácia da terapêutica alternativa ou complementar das cartas psicografadas que ele mesmo buscou como forma de autoajuda para transpor os obstáculos causados pelo LC.

É inegável a numerosa safra de obras literárias espíritas que versam sobre temas relacionados às psicografias que intencionam contribuir para a superação da dor do luto. No entanto, evidenciamos nesta pesquisa a inexistência de estudos acadêmicos científicos publicados que agreguem a psicografia de cartas mediúnicas aos temas saúde mental, luto e espiritualidade.

Identificamos um artigo que referencia psicografias que foram aceitas em juízo inocentando réus e no mesmo há o apontamento da opinião de que mensagens desta natureza auxiliam familiares na elaboração do luto (PEREIRA, 2014). Em outro trabalho, é mencionado superficialmente o fato de mães terem recebido mensagens confortantes de seus filhos falecidos através de contatos espirituais e sugere que esse modo de enfrentamento do luto pode facilitar reavaliaçôes positivas, diminuindo a intensidade do pesar (FRANQUEIRA et al., 2015). 
Para além, observamos que paradigmas estão sendo flexibilizados e ventilam avanços por meio do reconhecimento da subjetividade nos processos patológicos, fortalecendo teorias que caminham para a consolidação de propósitos que sugerem equivalência nas esferas espiritualistas e acadêmicas, o bem-estar físico e mental da humanidade.

\section{Conclusão}

Parece haver consenso quanto à inevitabilidade do luto; quanto ao seu elevado valor adaptativo quando decorre naturalmente, entendendo que cada indivíduo tem uma forma idiossincrática de vivenciar; e quanto à complexidade de se estipular exatamente o fim do processo. Contudo, neste estudo seguimos as diretrizes defendidas pelo DSM-5 ao concordamos que o auxílio terapêutico alternativo por meio da espiritualidade favorece o enfrentamento do LC, agregando novos saberes às psicopatologias fenomenológicas. Para além da compreensão do transtornar diante do enlutamento, buscamos a ênfase no efeito da vivência psicográfica na tentativa de alcançar o melhoramento.

Os profissionais da saúde, por meio do manual citado, já possuem indicativos científicos para a relevância das questóes que incluem a espiritualidade na otimização da qualidade de vida. Estes precisam reconhecer o real benefício para exploração deste quesito na programação terapêutica de qualquer doença (SAAD et al., 2001). Pesquisadores sugerem integrar o foco espiritual, independentemente de qual seja, ao processo de aconselhamento, permitindo ao cliente falar sobre suas experiências, dando sentido aos valores e atividades que auxiliam na solução de problemas clínicos (HOOK et al., 2013).

O estudo aqui apresentado é o primeiro trabalho científico de que se tem notícia que buscou relacionar LC e psicografia de entes queridos falecidos como meio para promoção da saúde emocional. A investigação constatou que as mensagens mediúnicas possuem potencial capaz de melhorar os sintomas deletérios ocasionados pelo transtorno nos destinatários que as recebem por meio presencial. Consideramos comprovada a validade da máxima popular que interpreta as cartas psicografadas com sendo "consoladoras".

A constatação do fato na verdade da experiência dos voluntários aqui analisados sugere que a partir desta comunicação os mesmos encontraram um caminho para (res) significar suas "perdas". No entanto, isso não representa a ocorrência da finalização 
da adversidade. Nessa perspectiva, vale salientar que a "Carta Consoladora" não pode ser considerada uma indicação terapêutica, visto que sua emissão depende de fatores que ainda estão longe de serem compreendidos, mas sim um meio capaz de atenuar a dor emocional quando se tem acesso. Portanto, o que demonstramos neste estudo foi a sua legitimidade em potencializar o consolo nos portadores de LC.

Recentes estudos entendem o enlutamento complexo como uma situação inconclusiva que não alcança a retomada de um estado prévio ao considerar que a vida nunca mais será a mesma diante da ausência do ser amado, sendo necessário apreender o luto na contemporaneidade, sob a ótica do estranhamento, desnaturalizando a suposta universalidade (MACHADO; MENESES, 2018). Um ideal de consolação foi liberto pela psicanálise e estimulou a expectativa da superação racional da dor, propondo um dispositivo para a elaboração psíquica desta. Contudo, a medicina da alma continua a nos inspirar a reformulação de antigas tradiçôes sobre o luto "normal" e o transtornado (SILVA, 2007).

Ensejamos que este estudo contribua para que a rede de atendimento ao luto amplie o entendimento, as estratégias de acolhimento da dor e de suas experiências, interpretando individualmente o estado do enlutado. Atendendo o LC de maneira holística ou gestáltica, ao compreender de forma global o fenômeno, o problema receberá o cuidado que merece, livre de tendências e açôes exclusivamente patologizantes, valorizando cuidados e intervençôes em saúde considerando os aspectos espirituais em todos os níveis e disciplinaridades assistenciais.

Espera-se com os resultados desta pesquisa o reconhecimento, a partir do universo que envolve a busca pessoal pelo alívio do sofrimento, de um dos canais (a psicografia) como fonte adjutória para o indivíduo processar os sentimentos relacionados ao LC, auxiliando assim no amplo debate que no momento decorre sobre o tema em diversas áreas de estudos. Assim, sugerimos que novas pesquisas foquem o consolo por meio da espiritualidade em sua vasta dimensão. ${ }^{2}$

\section{Referências}

ALVES, T. M. Formação de indicadores para a psicopatologia do Luto. Tese (Doutorado em Psiquiatria) - Faculdade de Medicina, University of São Paulo, São Paulo, 2014. Disponível em: <https://www.teses.usp.br/teses/disponiveis/5/5142/tde24022015112852/publico/ TaniaMariaAlvesVersaoCorrigida.pdf>. Acesso em: 21 jul. 2017. doi:10.11606/T.5.2014. tde-24022015-112852. 
AMERICAN PSYCHIATRIC ASSOCIATION. Diagnostic and statistical manual of mental disorders (5st ed). Arlington: Va, 2013.

ARRIBAS, C. da G. Espiritismo: entre crime e religião. Mneme-Revista de Humanidades, v. 11, n. 29, 2011. Disponível em: <https://periodicos.ufrn.br/mneme/article/view/956>. Acesso em: 8 dez. 2018.

AUBRÉE, M., LAPLANTINE, F. A mesa, o livro e os espiritos. Maceió: EDUFAL, 2009.

BARNETT, J. E.; JOHNSON, W. B. Integrating Spirituality and Religion into Psychotherapy: Persistent Dilemmas, Ethical Issues, and a Proposed Decision-Making Process. Ethics \& Behavior, v. 21, n. 2, p. 147-164, 2011. Disponível em: <https://www.tandfonline.com/doi/abs /10.1080/10508422.2011.551471>. Acesso em: 5 nov. 2018. https://doi.org/10.1080/10508422 .2011 .551471 .

BOUSSO, R. S. A complexidade e a simplicidade da experiência do luto. Acta paul. enferm. São Paulo, v. 24, n. 3, p. VII-VIII, 2011. Disponível em: <http://www.scielo.br/scielo.php?script=sci_ arttext\&pid=S0103-21002011000300001\&lng=en\&nrm=iso >. Acesso em: 01 jul. 2017. http:// dx.doi.org/10.1590/S0103-21002011000300001.

BOWLBY, J. Apego e perda. v. 3: Perda, tristeza e depressão. São Paulo: Ed. Martins Fontes, 1985.

BUENO, I. J. Morte e luto na contemporaneidade: a influência da espiritualidade na superação da perda. São Leopoldo. RS: Faculdades EST, v. 2, p. 67-84, 2014. Disponível em: <http:// anais.est.edu.br/index.php/congresso/article/view/232>. Acesso em: 5 nov. 2018.

CÂMARA, F. P. A 11ª Classificação Internacional de doenças da OMS. Psychiatry on line Brasil, 2018. Disponível em: <https:/www.polbr.med.br/2018/07/02/a-11a-classificacaointernacional-de-doencas-da-oms>. Acesso em: 30 out. 2018.

CURRIER, J.; NEUMEYER, R.; BERMAN, J. The effectiveness of psychotherapeutic interventions for bereaved persons: A comprehensive quantitative review. Psychological Bulletin, v. 134, n. 5, p. 648-661, 2008. Disponível em: <https://psycnet.apa.org/record/2008-11487-002>. Acesso em: 8 dez. 2018. https://doi.org/10.1037/0033-2909.134.5.648.

DELALIBERA, M. et al. Adaptação e validação brasileira do instrumento de avaliação do luto prolongado: PG-13. Psicologia: teoria e prática, v. 19, n. 1, p. 94-106, 2017. Disponível em: <https://www.redalyc.org/pdf/1938/193851916006.pdf>. Acesso em: 8 dez. 2018. https:// dx.doi.org/10.5935/1980-6906/psicologia.v19n1p94-106.

FEDERAÇÃO ESPÍRITA BRASILEIRA. FEB. Conteúdo espirita em artigos, notícias, estudo, pesquisa, especialmente para você. 2016. Disponível em: <https://www.febnet.org.br/portal/>. Acesso em: $1^{\circ}$ jul. 2017.

FRANCO, M. H. P. Formação e rompimento de vínculos: o dilema das perdas na atualidade. São Paulo: Summus, 2010. 
FRANQUEIRA, A. M. R.; MAGALHÃES, A. S.; FÉRES-CARNEIRO, T. O luto pelo filho adulto sob a ótica das mães. Estud. Psicol. (Campinas), v. 32, n. 3, p. 487-497, 2015. Disponível em: <http://www.scielo.br/scielo.php?script=sci_arttext\&pid=S0103-166X2015000300487\&ln $\mathrm{g}=$ en\&nrm=iso>. Acesso em: 0 dez. 2018. https://doi.org/10.1590/0103-166X2015000300013.

FREIRE, T.; ALMEIDA, L. S. Metodologia da Investigação em Psicologia e Educação. Portugal: Psiquilíbrios, 2008.

FREITAS, J. L.; MICHEL, L. F. A maior dor do mundo: o luto materno em uma perspectiva fenomenológica. Psicol. Estud., Maringá, v. 19, n. 2, p. 273-283, 2014. Disponível em: <http:// www.scielo.br/scielo.php?script=sci_arttext $\&$ pid $=$ S1413-73722014000200010\&lng=en \&nrm $=$ iso>. Acesso em: 8 dez. 2018. https://doi.org/10.1590/1413-737222324010.

FREUD, S. Luto e melancolia [1915]. In: . Edição standard brasileira das obras psicológicas completas de Sigmund Freud, v. 24. Rio de Janeiro: Imago, 1996.

FUJISAWA, D. et al. Prevalence and determinants of complicated grief in general population. Journal of Affective Disorders, v. 127, n. 1-3, p. 352-358, 2010. Disponível em: <https://www. sciencedirect.com/science/article/abs/pii/S0165032710004210>. Acesso em: 10 jul. 2017. doi: 10.1016/j.jad.2010.06.008.

HOOK, J. N.; WORTHINGTON, E. L. J.; DAVIS, D. E. Religion and Spirituality in Counseling. In: FOUAD, N. A. (Ed.). APA Handbook of Counseling Psychology: Practice, Interventions, and Applications, v. 2, p. 417-432, 2013. Disponível em: < https://psycnet.apa. org/record/2012-03487-017>. Acesso em: 8 dez. 2018. https://doi.org/10.1037/13755-017.

INSTITUTO BRASILEIRO DE GEOGRAFIA E ESTATÍSTICA. Censo Demográfico 2010: características gerais da população, religião e pessoas com deficiência. Brasília, 2010. Disponível em: <https://www.ibge.gov.br/>. Acesso em: 10 jun. 2017.

KARDEC, A. O livro dos médiuns. Rio de Janeiro: FEB, 1984.

KARDEC, A. O livro dos espíritos. Rio de Janeiro: FEB, 2007.

LEMMENS, J.; VALKENBURG, P.; GENTILE, D. The Internet Gaming Disorder Scale. Psychological Assessment, v. 27, n. 2, p. 567-582, 2015. Disponível em: < https://psycnet.apa.org/ record/2014-57712-001>. Acesso em: $1^{\circ}$ dez. 2018. https://doi.org/10.1037/pas0000062.

LUNA, I. J. Histórias de perdas: uma proposta de (re)leitura da experiência de luto. Tese (Doutorado) - Universidade Federal de Santa Catarina, Centro de Filosofia e Ciências Humanas, Programa de Pós-Graduação em Psicologia, Florianópolis-SC, 2014. Disponível em: <https:// repositorio.ufsc.br/handle/123456789/129248>. Acesso em: 15 jul. 2017.

MACCALLUM, F.; BRYANT, R. Autobiographical memory following cognitive behaviour therapy for complicated grief. Journal of Behavior Therapy And Experimental Psychiatry, v. 42, n. 1, p. 26-31, 2011. Disponível em: < https://www.sciencedirect.com/science/article/abs/pii/ S0005791610000832>. Acesso em: 15 jul. 2017. https://doi.org/10.1016/j.jbtep.2010.08.006. 
MACHADO, R.; MENEZES, R. Gestão Emocional do Luto na Contemporaneidade. Revista Ciências da Sociedade, v. 2, n. 3, p. 65, 2018. Disponível em: <https://www.researchgate.net/ profile/Rachel_Aisengart_Menezes/publication/328059297_Gestao_Emocional_do_Luto_ na_Contemporaneidade/links/5bc911be299bf17a1c5f6cc7/Gestao-Emocional-do-Luto-naContemporaneidade.pdf >. Acesso em: 10 jul. 2017. https://doi.org/10.30810/rcs.v2i3.622.

MORELLI, A. B.; SCORSOLINI-COMIN, F.; SANTOS, M. A. Impacto da morte do filho sobre a conjugalidade dos pais. Ciência \& Saúde Coletiva, v. 18, n. 9, p. 2711-2720, 2013. Disponível em: <https://www.scielosp.org/pdf/csc/2013.v18n9/2711-2720/pt >. Acesso em: 18 dez. 2018. https://dx.doi.org/10.1590/S1413-81232013000900026.

NUNES, F. D. D. et al. O fenômeno do suicídio entre os familiares sobreviventes: revisão integrativa. Revista Portuguesa de Enfermagem de Saúde Mental, Porto, v.15, p.17-22, 2016. Disponível em: <http://www.scielo.mec.pt/scielo.php?script=sci_arttext\&pid=S1647216020 16000100003\&lng=pt\&nrm=iso>. Acessos em: 20 nov. 2018. http://dx.doi.org/10.19131/ rpesm.0127.

ORGANIZAÇÃO MUNDIAL DA SAÚDE. CID-10 - Classificação estatística internacional de doenças e problemas relacionados à saúde. São Paulo: EDUSP, 1999.

PANZINI, R. G.; BANDEIRA, D. R. Coping (enfrentamento) religioso/espiritual. Rev. psiquiatr. clín. São Paulo, v. 34, supl. 1, p. 126-135, 2007. Disponível em: <http://www.scielo. br/scielo.php?script=sci_arttext\&pid=S0101-60832007000700016\&lng=en\&nrm=iso $>$. Acesso em: 10 dez. 2018. https://doi.org/10.1590/S0101-60832007000700016.

PARGAMENT, K.; LOMAX, J. Understanding and addressing religion among people with mental illness. World Psychiatry, v. 12, n. 1, p. 26-32, 2013. Disponível em: <https:// onlinelibrary.wiley.com/doi/full/10.1002/wps.20005 >. Acesso em: $10 \mathrm{dez}$. 2018. https://doi. org/10.1002/wps.20005.

PARKES, C. A historical overview of the scientific study of bereavement. Handbook Of Bereavement Research: Consequences, Coping, and Care, p. 25-45, 2001. Disponível em: <https://psycnet.apa.org/record/2001-18149-001>. Acesso em: 10 dez. 2018. https://doi. org/10.1037/10436-001.

PEREIRA, A. G. Justiça na religião e conforto no sistema judiciário: relações político-religiosas entre familiares de vítimas da violência urbana no Rio de Janeiro. Revista Intratextos, v. 5, n. 1, p. 29-45, 2014. Disponível em: < https://repositorio.ufma.br/jspui/handle/123456789/706 >. Acesso em: $1^{\circ}$ dez. 2018. http://dx.doi.org/10.12957/intratextos.2014.10517.

PEREIRA, C. B. et al. O processo de luto inerente à morte da infância à velhice. Universidade Lusíada de Lisboa, v. 5, n. 2, p. 31-42, 2015. Disponível em: <http://hdl.handle.net/11067/1343>. Acesso em: $1^{\circ}$ dez. 2018. 
PRIGERSON, H. et al. Prolonged Grief Disorder: Psychometric Validation of Criteria Proposed for DSM-V and ICD-11. Plos Medicine, v. 6, n. 8, 2009. Disponível em: <https://www.ncbi. nlm.nih.gov/pmc/articles/PMC3867550/>. Acesso em: 08 dez. 2018. https://doi.org/10.1371/ journal.pmed.1000121.

REBELO, J.; LANCMAN, S.; BATISTA, M. Perspectivas sobre as estruturas não governamentais e a ação comunitária no apoio ao luto sadio em Portugal e o "Modelo Vivencial do Luto Sadio". Revista de Terapia Ocupacional da Universidade de Sáo Paulo, v. 28, n. 1, p. 1-8, 8 jun. 2017. Disponível em: <http://www.periodicos.usp.br/rto/article/view/127282>. Acesso em: 20 jun. 2017. https://doi.org/10.11606/issn.2238-6149.v28i1p1-8.

ROCHA, D. D. et al. Sentimentos vivenciados pelos profissionais de Enfermagem diante de morte em unidade de terapia intensiva neonatal. Mental. Barbacena, v. 11, n. 21, p. 546-560, 2017. Disponível em: <http://pepsic.bvsalud.org/scielo.php?script=sci_arttext\&pid=S1679442 72017000200015\&lng=pt\&nrm=iso $>$. Acesso em: 10 nov. 2018.

ROGERS, C. et al. Long-term effects of the death of a child on parents' adjustment in midlife. Journal of Family Psychology, v. 22, n. 2, p. 203-211, 2008. Disponível em: <https://psycnet.apa. org/doiLanding?doi=10.1037\%2F0893-3200.22.2.203>. Acesso em: 15 nov. 2018. https://doi. org/10.1037/0893-3200.22.2.203.

SAAD, M.; MASIEIRO, D.; BATTISTELLA, L. Espiritualidade baseada em evidências. Acta Fisiátrica, v. 8, n. 3, 2001. Disponível em: < https://www.revistas.usp.br/actafisiatrica/article/ view/102355>. Acesso em: 15 jun. 2017. https://doi.org/10.5935/0104-7795.20010003.

SANTOS, K. As representaçóes de uma população acerca do suicídio. Trabalho de Conclusão de Curso. Universidade de Santa Cruz do Sul, 2017. Disponível em: <http://hdl.handle. net/11624/1702>. Acesso em: 3 nov. 2018.

SILVA, C. A. A prática da psicografia: corpo e transmissão em relatos de experiência mediúnica. Tese (Doutorado) - Universidade Estadual Paulista "Júlio de Mesquita Filho", 2016. Disponível em: <http://hdl.handle.net/11449/143425>. Acesso em: 10 jun. 2017.

SILVA, P. J. C. O ideal da consolação e a paixão pela morte. Rev. latinoam. psicopatol. fundam. São Paulo, v. 10, n. 1, p. 146-154, 2007. Disponível em: <http://www.scielo.br/scielo. php?script $=$ sci_arttext $\&$ pid $=S 1415-47142007000100146 \& \operatorname{lng}=$ en $\& \mathrm{nrm}=\mathrm{iso}>$. Acesso em: 10 jun. 2017. http://dx.doi.org/10.1590/141547142007001013.

STRUCKEL, E. R. T.; SILVA, A. L. A.; ZANDONADI, A. C. Transtorno obsessivo compulsivo: acumulação, a outra face do consumismo. Revista Farol, v. 3, n. 3, 2017. Disponível em: <http:// www.revistafarol.com.br/index.php/farol/article/view/40/0>. Acesso em: 15 dez. 2018.

TORRES, N. Luto: a dor que se perde com o tempo (...ou não se perde?). Londrina: IACEP, 2013. 
WALSH, F.; MCGOLDRICK, M. A Family Systems Perspective on Loss, Recovery and Resilience. In: SUTCLIFFE, P.; TUFNELL, G.; CORNISH, U. (Eds.). Working with the Dying and Bereaved. Palgrave, London, p. 1-26, 1998. Disponível em: <https://doi.org/10.1007/978-1349-26222-9_1>. Acesso em: 10 jun. 2017.

WITTOUCK, C. et al. The prevention and treatment of complicated grief: A metaanalysis. Clinical Psychology Review, v. 31, n. 1, p. 69-78, 2011. Disponível em: <https://www. sciencedirect.com/science/article/abs/pii/S0272735810001492>. Acesso em: 15 jun. 2017. https://doi.org/10.1016/j.cpr.2010.09.005.

WORDEN, J. Grief Counseling and Grief Therapy. A Handbook for the Mental Health Practitioner. London: Routledge, 1991.

ZISSOK, S.; SHEAR, K. Grief and bereavement: what psychiatrists need to know. World Psychiatry, v. 8, n. 2, p. 67-74, 2009. Disponível em: <https://www.ncbi.nlm.nih.gov/pmc/ articles/PMC2691160/>. Acesso em: 15 jul. 2017. doi: 10.1002/j.2051-5545.2009.tb00217.x.

\section{Notas}

${ }^{1}$ Agradecimentos a: Ajenário Teixeira Miranda (in memoriam), Lenira Cardoso (in memoriam), Nathanael (espírito), Abelha - André Bráulio dos Santos (in memoriam), Orlando Noronha Carneiro, Centro Espírita Luiz Gonzaga - Pedro Leopoldo-MG, Associação Beneficente Espírita Caminheiros do Bem Curitiba-PR, Pronto Socorro Espiritual Pais e Filhos - Osasco-SP, Grupo Espírita Eurípedes Barsanulfo - Santa Luzia-MG, Luiz Flávio Hott, Maria Glória Cardoso de Miranda e a todos os colaboradores, os voluntários do estudo e seus entes queridos (in memoriam).

${ }^{2}$ M. C. M. Hott e A. M. dos S. Reinaldo foram igualmente responsáveis pela concepçáo, planejamento e execução do trabalho; análise e interpretação dos resultados; redação, revisão intelectual e aprovação final do artigo. 


\section{Abstract}

\section{The consoling potential of psychographed letters in the emotional health of bereaved people} The research aimed to know the emotional state of people in complicated mourning who receive letters written by mediums, whose emission was attributed to their deceased ones. This is a qualitative study with a quantitative approach, carried out with 48 volunteers in three scenarios - one virtual and two in person. These responded to structured forms composed of nine questions that defined the profile of the participants; and 17 questions about grief, elaborated according to the criteria of the Diagnostic and Statistical Manual of Mental Disorder (DSM-5), which verified feelings before and after mediumistic communication. We conclude that the messages contributed to improve the emotional health of people from face-to-face settings, positively interfering in the quality of life, validating the concept of "Consoling Letters".

> Keywords: mental health; complicated mourning; spirituality; psychography. 